\title{
RETRACTED ARTICLE: Real-time eye detection in multimedia environment
}

\section{Zepeng Wang ${ }^{1}$ (D) $\cdot$ Luming Zhang ${ }^{1}$}

Received: 15 September 2017 /Revised: 27 September 2017 / Accepted: 29 September 2017 /

Published online: 19 October 2017

(C) Springer Science+Business Media, LLC 2017

The Editor-in-Chief has retracted this article [1], which was published as part of special issue "Multi-source Weak Data Management using Big Data", because there was evidence of manipulation of the peer review process.

Author Zepeng Wang stated on behalf of both authors that they agree to this retraction.

\section{References}

1. Wang, Z. \& Zhang, L. Real-time eye detection in multimedia environment. Multimed Tools Appl (2017). https://doi.org/10.1007/s11042-017-5268-7

Electronic supplementary material The online version of this article (https://doi.org/10.1007/s11042-0175268-7) contains supplementary material, which is available to authorized users. 